\title{
An Empirical Analysis and Time Distribution of Deviant Homicides in Houston: A Time Series Observational
}

\section{Study}

\author{
G. Solomon Osho \\ Prairie View A\&M University, Jonathan Hyde, Texas Southern University
}

Accepted: March 11, 2013 Published: April 25, 2013

Doi:10.5296/jsr.v4i1.3173

URL: http://dx.doi.org/10.5296/jsr.v4i1.3173

\begin{abstract}
During the late 1970's and throughout the 1980's the United States economy was struggling. When the oil crisis in 1973 began, the economy in Houston was severely affected. During the period 1973-1985 homicides in the state of Texas rose from 1506 to 2132, an increase of 41 percent (US Department of Justice, 2008), however, there was decline in murder rates nationally from 19,640 in 1973 to 18,980 in 1985, a decrease of five percent (US Department of Justice, 2008). This research will examine what motivates members of the Houston community to inflict violence upon their neighbors. The age and race of the victims will be considered as reasoning for homicidal acts, and compared to the age and race of the suspects. The victim/offender relationship will be looked at in attempt to determine if more homicides are committed upon strangers or acquaintances. This study was able to determine when the crime peaked, resulting in suggestions for future studies. However, while we did not find the correlation, this research was not at all a loss. We were able to determine when the crime peaked, resulting in suggestions for future studies.
\end{abstract}

Keyword: Homicide, victim/offender relationship, Juveniles

\section{Introduction}

During the late 1970's and throughout the 1980's the United States economy was struggling. When the oil crisis in 1973 began, the economy in Houston was severely affected. As the economy was unpredictable and gasoline was hard to come by, people resorted to crime to provide for themselves, not only their needs, but also their selfish desires, their wants. During the period 1973-1985 homicides in the state of Texas rose from 1506 to 2132, an increase of 41 percent (US Department of Justice, 2008), however, this rise in the homicide of murders in Texas can be explained a number of different ways. More access to guns and other weapons could be a possible explanation. The racial diversity amongst Texas residents could also explain the rise in homicide rates. Many may feel that the reason for the increase in 
violence from 1973-1985 was due to the abundance of recreational drug use. However, there was decline in murder rates nationally from 19,640 in 1973 to 18,980 in 1985 , a decrease of five percent (US Department of Justice, 2008).

In 1985, the trend turned around, as the state of Texas began to see decreasing numbers of homicides. From the period of 1985-1994 the number of homicide rates decreased from 2,132 to 2,022, a drop of six percent. Nationally, homicide was on the rise, as the number of homicides increased from 18,980 to 23,330 , a rise of 23 percent.

The reversal in the trend was great news for the people of the state of Texas. Homicide rates were dropping, and continued to do so until 2007. 1994 was a peek year for homicides in the United States, as they have declined since that time (US Department of Justice, 2008). This research will examine the cause for homicides in the city of Houston from 1985-1994. It will consider many reasons why a person may find himself or herself to be a victim of homicide. There are many reasons why an unfortunate individual may become a victim. This research will examine what motivates members of the Houston community to inflict violence upon their neighbors. The age and race of the victims will be considered as reasoning for homicidal acts, and compared to the age and race of the suspects. The victim/offender relationship will be looked at in attempt to determine if more homicides are committed upon strangers or acquaintances.

\section{Prior Literature Review}

In 2007 1,132 people under the age of 18 were arrested in the United States for murder (US Department of Justice, 2007). While this number may seem high, it is actually low compared to previous years. In 1993, the number of youth arrested for murder reached a 25-year high a t 3,284 (Heide, 1997). In 1993 one out of every six people in the United States arrested for murder was under age 18. While juvenile murder rates are down as a whole, the United States saw a rise in black males as victims of homicide by $31 \%$ from 2002-2007. There was also an increase in black males as perpetrators by $43 \%$. Throughout these increases in black male juvenile murders, the handgun has remained the weapon of choice. In this subgroup, during this time, gun killings has risen 54\% when black males are the victims, and $47 \%$ when they are the perpetrators (Fox \& Swat, 2008).

Many factors determine why juveniles decide to kill. Heide (1997) gave five explanations of why youth kill: situational factors, societal influences, resource availability, personal characteristics, and cumulative effects. Some situational factors that may account for juveniles deciding to kill are; child abuse, neglect, or exposure to violence. Kids mimic the behaviors of adults they come in contact with. When a child is exposed to large amounts of violence in the home, he/she may get the message that it is okay to resort to violence under certain circumstances. Societal influences come into play in promoting violence when a child listens to rap music, and the lyrics include killing, stealing, and dealing drugs. Lack of good role models can lead children to become violent. Resource availability is important to consider, 
when trying to make a determination of why youth kill. The availability and ease of locating guns may contribute to the rising number of homicide rates involving guns. Large amounts of drugs and alcohol on the street, may also account for rising homicide rates involving black youth. Personal characteristics of the perpetrator affect the decision of a youth to commit homicide. A youth's self-esteem, bad judgment, and lack of being able to handle negative emotions have accounted for a large number of juvenile homicides. Cumulative effects cannot be left out, when attempting to attempt to determine, why youth kill. Many homicides involving youth are caused by prejudice, hatred, or a biological connection.

In 1973 there were 60,000 reported cases of child abuse and neglect in the United States; in 1993 there were over 3,000,000. Heide (1997) pointed out that those victimized, as children are more likely to have an anti-social disorder. As the statistics have shown, the homicide rates have increased with the child abuse and neglect rates. Children who witness acts of violence in their homes are twice as likely to commit acts of violence.

Juveniles that decide to kill create a serious dilemma for the juvenile justice system. Judges must decide what to do with juveniles that commit murder. The rehabilitation of the juvenile is the priority is determining the outcome of these juveniles. When attempting to determine what is in the best interest of the child, you have to determine what threat to society this juvenile has, and what can be done to rehabilitate them. According to Rowley, (1987) many juvenile killers suffer from neurosis, psychoses, personality disorder, and organic brain syndromes. This should show us that tax dollars could be well spent treating mental illness but many cases of parricide in the United States are the result of brutal parental mistreatment.

Rowley (1987) found that youth that killed their parents demonstrated fewer indications of poor impulse control, a variable in many youth killings, but high amounts of evidence of having been physically or sexually abused by their parents. In other words, poor impulse control can be blamed for youth killing, but not in most cases of parricide. With around 2,000 juvenile homicides committed annually, child abuse is to blame along with easy access to guns.

This research will examine juvenile homicides in the Houston area, with special interest in black juvenile homicides. Using official criminal statistics, an attempt will be made to determine what factors were present and contributed to a large number of these homicides. By evaluating the homicides data from the Houston area, an attempt to determine which variables contributed most to homicides involving black juveniles. By determining which factors most contributed to these specific homicides, we can be better equipped to prevent juvenile homicides involving black juveniles.

\section{Methods}

Data for this research was obtained through the National Archive of Criminal Justice Data. The data was taken from homicide police records in the city of Houston, Texas in the 
years from 1985 through 1994. For the purposes of this research, a juvenile is defined as someone who has not reached 20 years of age, in other words 19 and younger. From the year 1985 to 1994, the city saw a fluctuation in homicide rates with juveniles as suspects with a peek year in 1991. Table one shows the years during the period of 1985 to 1994 in which most homicides occurred in Houston that had black juveniles as suspects.

\begin{tabular}{lcc}
\hline \multicolumn{3}{l}{ Table 1. Year in Which Homicide Occurred } \\
\hline Year & Frequency & Percent $(\%)$ \\
\hline & & \\
1985 & 40 & 5.9 \\
1986 & 32 & 4.7 \\
1987 & 34 & 5.0 \\
1988 & 37 & 5.5 \\
1989 & 57 & 8.4 \\
1990 & 95 & 14.0 \\
1991 & 122 & 18.0 \\
1992 & 84 & 12.4 \\
1993 & 96 & 14.2 \\
1994 & 81 & 11.9 \\
\hline
\end{tabular}

An examination of table one shows that during the period of 1985 to 1994, the city of Houston saw an increase in of over $100 \%$ in yearly homicides when juveniles were the suspects. In 1985 Houston witnessed 40 homicides meeting these criteria, and by the end of the study, in 1994 there were over 81. During this time the city of Houston averaged 67.8 homicides per year in which the victims were juveniles.

Homicides committed by juveniles remained consistent throughout the year. Table two shows that the month had little effect on the number of homicides committed by juveniles. Although the number of homicides remained consistent, they were slightly higher in the summer months.

Table 2. Month in Which Homicide Occurred

\begin{tabular}{lcc}
\hline Month & Frequency & Percent $(\%)$ \\
\hline January & 58 & \multicolumn{2}{c}{8.6} \\
February & 51 & \multicolumn{2}{c}{7.5}
\end{tabular}


March

April

May

June

July

August

September

October

November

December
6.2

7.5

\section{7}

8.4

11.4

\section{8}

8.6

6.9

8.7

An examination of table two shows that during the period of 1985 to 1994 , the city of Houston saw a slight increase in homicides during the summer months. This could be due to the hot weather and the increased anger and aggression that are present during times of extreme heat. These higher rates in the summer may be due to lack of structure, as school is not in session during the months of June through August. The day of the week was considered as a variable. It is another indication that lack of school may have led to juveniles committing homicides. Table three shows the number of homicides committed by juveniles during the week compared to on the weekend when there is no school.

Table 3. Day of the Week Homicide Occurred

\begin{tabular}{lrr}
\hline Day & Frequency & Percent $(\%)$ \\
\hline Weekday & 342 & 50.4 \\
Weekend & 336 & 49.6 \\
\hline
\end{tabular}

An examination of table three shows that almost half of all homicides during the period of 1985 to 1994 occurred on the weekend. It is for this reason and higher rates during the summer months, that we can conclude that school may contribute to the prevention of homicides when juveniles are the suspects. It is for this reason that there needs to be more constructive activities for juveniles to participate in away from school in the city of Houston. 
Table 4. Multivariate Correlation

(1)

Age of Suspect (1)

Year of Homicide (2)

Month of Homicide (3)

Day of Week (4)

Gang-Related (5)

Drug-Related (6)

Weapon Type (7)
(2)

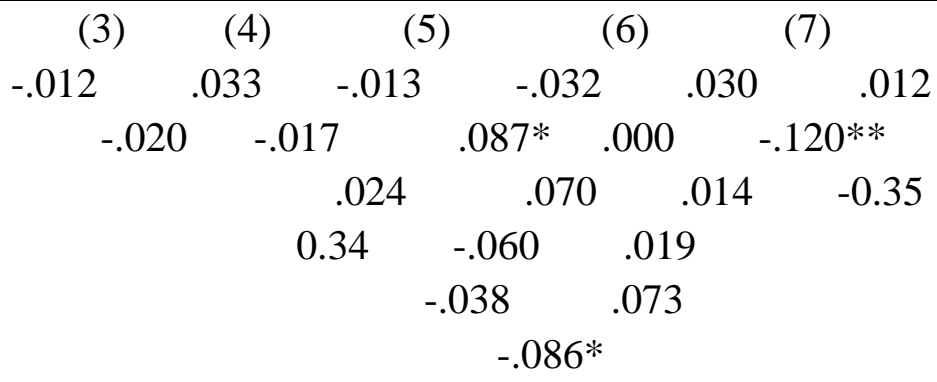

* Correlation is significant at the 0.05 level (2-tailed).

** Correlation is significant at the 0.01 level (2-tailed).

\section{Discussion}

A close examination of table four shows us that there is no strong positive correlation present amongst the variables examined and while few of the correlations are statistically significant, none of them are strong correlations. With this being a limitation of the study, we must rely on descriptive statistics alone to present our findings. As 1992 approached, we continued to see a dramatic increase in homicides amongst black juveniles in Houston, Texas, with a peek year in 1991. With the month witnessing the most homicide amongst black youth being August, the data provided in this research would suggest that there need to be more summer time activities.

However, because almost half of the homicide meeting these criteria occurred on the weekend, it would suggest that the youth need more structure for the weekend. It has been noted in the Kansas City Preventative Patrol Experiment (Davis \& Knowles, 1975) that increasing police presence will not deter crime in general. Although this study is accepted in the field of criminal justice, there is a possibility that the accuracy and policy implications may have changed through the years. Seeing that homicides occur at a much larger rate when these juveniles are not in school, it is obvious that these juveniles need to be accounted for. If the parents are not going to watch their children, it can be suggested that juvenile officers may be able to decrease juvenile homicides by having more of a presence in the community during the summer time and on the weekends. A suggestion for future study would include a modified replication of the Kansas City Preventative Patrol Experiment in Houston. If such an experiment did indeed find that more patrol would reduce crime, juvenile homicide in 


\section{Macrothink}

particular, then an effort to recruit and put on patrol, more juvenile officers would prove to be beneficial.

We saw juvenile homicide by black youth peek in 1992 and decrease thereafter. Another suggestion for future study would be to attempt to determine the dependent variables that accounted for the decrease starting in 1992. If the variables could be found, then continuance of what is working should be suggested to the police in Houston.

\section{Conclusion}

In performing the multivariate correlation, we hoped to find a strong positive correlation amongst a dependent variable and homicides committed by black juveniles in Houston. We were unable to do so, and had to rely on descriptive statistics. While we did not find the correlation, this research was not at all a loss. We were able to determine when the crime peaked, resulting in suggestions for future studies. We also were able to determine that almost half of the homicides meeting these criteria were committed on the weekend, and the peek month for the year being August. By discovering this, we are able to better understand what we as criminologist need to research in the future to prevent homicide in the future.

\section{References}

Cornell, D. (1993). Juvenile homicide: A growing national problem. Behavioral Sciences \& the Law, 11, 389-396.

Davis, E.M., \& Knowles, L. (1975). A critique of the report: An evaluation of the Kansas City Preventative Patrol Experiment. The Police Chief, 42: 31-32

Heide, K. (1997, March). Juvenile homicide in America: How can we stop the killing? Behavioral Sciences \& the Law, 15(2), 203-220.

Rowley, J., Ewing, C., \& Singer, S. (1987). Juvenile homicide: The need for an interdisciplinary approach. Behavioral Sciences \& the Law, 5(1), 3-10

U.S. Department of Justice (2009). Bureau of Justice Statistics. Retrieved May 15, 2009, from Bureau of Justice Statistics Web site: http://www.ojp.usdoj.gov/bjs/ 